\title{
Além do sertão: indígenas no Brasil do século XIX
}

\section{Fernanda Sposito*}

\author{
Universidade Federal de São Paulo \\ São Paulo - São Paulo - Brasil
}

Resenha do livro: AMOROSO, Marta. Terra de índio: imagens em aldeamentos do Império. São Paulo: Terceiro Nome, 2014.

Conheçamoso projeto de uma fazenda ideal, imaginada por um francês no Brasil durante a primeira metade do século XIX. O sujeito pensou-a cercada por um cenário paradisíaco na Serra da Mantiqueira, interior de Minas Gerais. Seria uma fazenda produtiva e assentada em terras férteis. Para viabilizar tal prosperidade, o francês acreditava ser possível manter índios e negros em paz, submissos a eleetrabalhando demaneira eficiente. Os africanosescravizados, abenevolênciadeseusenhorfariaqueelesseportassem de maneira cordata, retribuindo com dedicação ao trabalho. Já os índios, estes deveriam ser atraídos com presentes. Uma vez que se tornassem aliados, o caminho para sua submissão seria a catequese (p.38-39). Esse foi um projeto idílico de Auguste de Saint-Hilaire, botânico que viajou por diversas partes do Brasil entre 1816 e 1822, coletando milhares de espécies vegetais e animais, escrevendo relatos. Seus textos são alguns dos mais preciosos escritos

* Pesquisadora de Pós-Doutorado em História na Unifesp. Bolsista FAPESP. E-mail: fifaspo@yahoo.com.br. 
sobre o Brasil no século XIX. Apresentam elementos não só sobre a fauna, a flora eageografiadoterritório, mastambém sobreaspopulações dossertões do Brasil, incluindo os povos indígenas das várias províncias que conheceu.

O projeto idílico da fazenda Saint-Hilaire, nunca realizado, era apenas uma miragem, uma idealização de como controlar a natureza submetendo-a aos interesses da ciência e do desenvolvimento econômico. Dentro dessa visão, alguns cientistas como ele acreditavam que os povos ameríndios representavamumestágiodedegeneraçãodaespéciehumanaequecabiaaos povos europeus encontrar caminhos para os "civilizar".

Apassagem descritaacimaéumadaspreciosidadesapresentadaseanalisadasnestenovotrabalho de Marta Amoroso, publicadoem 2014elançado em 2015 pela editora Terceiro Nome. Com base em arquivos sediados em diferentes países, em especial a documentação da Ordem Menor dos Frades Capuchinhos, de orientação franciscana, sediada no Rio de Janeiro (Arquivo da Custódia dos Padres Capuchinhos no Rio de Janeiro), - Amoroso escreveu uma importante contribuição aos estudos sobre os índios do século XIX. Utilizando-se das ferramentas teóricas da Antropologia, relendo os estudos clássicos de Telêmaco Borba e Curt Ninuemdaju sobre os Guarani no início do século XX, a autora visa não só descrever as políticas de Estado e os dilemas que os freis enfrentaram nos interiores do Brasil, principalmente no Paraná,masproblematizarcomooscoletivosindígenas(termouptodateentreos etnólogosparasereferiraosgruposindígenas) seinseriramnosaldeamentos.

Os aldeamentos no Império do Brasil foram um novo-velho modelo de controle dos índios. A política das aldeias sob controle dos brancos no XIX pode ser lida no sentido de uma reedição, uma espécie de mescla de referências jesuíticas e pombalinas do período colonial. Ao mesmo tempo, traz as novidades de um Estado nacional que buscava controlar as populações do território que pretendia como seu, dinamizando a economia dessas regiões dentro da lógica produtiva do capitalismo. Além disso, a autora mapeia os fundamentos científicos queembasaram as ações dos viajantes europeus ao Brasil no XIX, das concepções dos padres capuchinhos e das formas como os diferentes grupos indígenas traduziam e se inseriam nas novas situações.

Marta Amoroso é antropóloga, professora titular do Departamento de Antropologia da Universidade de São Paulo. Defendeu o seu mestrado na 
Unicamp, sob orientação de Roberto Cardoso de Oliveira, estudando o povo Mura na Amazônia no século XVIII. No doutorado, na USP, sob orientação de Manuela Carneiro da Cunha, fez uma etnografia do aldeamento São Pedro de Alcântara (1855-1895), onde viveram populações Guarani, Kaiowá e Kaingang na província do Paraná. Ingressou na USP como docente no ano de 2000. Desde então vem integrando importantes grupos de pesquisa, orientando pesquisadores e produzindo uma série de artigos e coletâneas centrados nos temas da Etnologia Indígena, História dos Índios no Brasil e estudos sobre os Mura na Amazônia. É uma das pesquisadoras principais do Centro de Estudos Ameríndios (CEstA) na USP, coordenado por Dominique Gallois.

A tese de doutorado de Marta Amoroso, "Catequese e evasão. Etnografia do aldeamento indígena de São Pedro de Alcântara, Paraná (18551895)", defendida na USP em 1998 é um estudo denso que articula dados de arquivos e levantamentos quantitativos por meio de uma refinada leitura etnográfica. Amoroso, ao longo de sua obra e especialmente em sua tese de doutorado,resolvemuitobemaleituradosdadosetnográficossobreassociedadesindígenas,conseguindofazeressesdadosseremcompreendidosdentro do contextoem queforam gerados. Realizaressetipo deanálisecomméritos tanto no campo da História como na Antropologia, à maneira de Manuela Carneiro da Cunha e Nádia Farage, é algo raro e merece ser celebrado. ${ }^{1}$

No entanto, a tese de doutorado de Marta Amoroso permanece inédita, pois o livro não éa tese, avisa a autora logo na introdução. Terra de índio:imagensemaldeamentosdolmpérioéumasíntesedosestudosrealizadosnosúltimos 20 anos pela autora. É certo que esses estudos se iniciam na tese, mas transcendem a ela. O presente livro, dividido em três partes, se propõe permitir uma melhor compreensão dos aspectos que cercaram seu objeto inicial, a experiência do aldeamento São Pedro de Alcântara no Paraná e os relatos

CUNHA, Manuela Carneiro da. (org.) História dos Índios no Brasil. São Paulo: Companhia das Letras/Fapesp/SMC, 1992 (como organizadora e autora de um dos capítulos); (org.). Legislação indigenista no séculoXIX.Uma compilação (1808-1889). São Paulo:Comissão Pró-Índio/ Edusp, 1992; FARAGE, Nádia. As Muralhas dos Sertões. Os Povos Indígenas no Rio Branco e a Colonização. Rio de Janeiro: Paz e Terra ANPOCS, 1991. 
do frei capuchinho Timotheo de Castelnuovo. É importante registrar que a não publicação da tese configura-se numa grande perda, pois ela é quase inacessível, estando disponível apenas para empréstimo físico na Biblioteca Florestan Fernandes da Faculdade de Filosofia, Letras e Ciências Humanas da USP.O banco de teses online da universidade não possui a tese de Amoroso em seu catálogo, visto que ela foi defendida antes de a USP implantar seu acervo digital de acesso universal.

Voltemos ao livro. A primeira parte, "Explorando a Mata Atlântica”, é composta pelos capítulos "O mal-estar de Guido Marlière" e "Dos Andes e Amazônia, rumo ao crânio botocudo". Discute os princípios científicos que respaldarama atuação demuitos viajantes estrangeirosatraídos para oBrasil depois da chegada da Corte portuguesa ao Rio de Janeiro. Énessa parte que está situada a análise da "fazenda imaginária" de Saint-Hilaire, mencionada no início desta resenha.

Jáa segunda parte,"Propondoa catequeseecivilização",integradapelos capítulos "Das selvas ao solo ubérrimo" "Descontinuidades”, aparece como um ensaio antropológico. Aqui a autora utiliza o conceito de "equivocações controladas", de Eduardo Viveiros de Castro, para pensar desencontros e traduçõesdentroeforadosaldeamentosentreosdiversoscoletivosindígenas, capuchinhos, escravos negros, imigrantes e demais moradores do entorno.

A terceira e última parte, "Construindo o aldeamento indígena", que contém os capítulos "Ficções em frei Timotheo de Castelnuovo"; "Lavoura (s)" e "Um kiki-koi para Arepquembe", é identificada pela própria autora como uma releitura de sua tese.

Como já mencionado, há várias passagens riquíssimas no livro. Destaco aqui o capítulo intitulado"Um kiki-koi para Arepquembe", em que Amoroso apresenta a forma como os Kaingang aldeados, mesmo já convertidos ao cristianismo, conseguem retomar um ritual funerário típico de seu grupo, o kiki-koi, para enterrar o cacique Manoel Arepquembe, assassinado em 1872. Uma das grandezas do capítulo está nas relações que a autora estabelece entre as doenças mortais que atingiram diversas vezes os índios dos aldeamentose de seu entorno eas releituras das mitologias defim de mundoentre os Guarani e Kaiowá. Outro aspecto analisado é que o modelo de missão do séculoXIXeliminou uma estratégia fundamental dos jesuítas no período co- 
Ionial, que era a tradução das línguas indígenas. No Oitocentos, isso resultou no fato de que os freis Timotheo de Castelnuovo e Luís de Cimitille tinham muito menos elementos para descrever e compreender os rituais funerários Kaingang do queos missionários de séculos anteriores tiveramem relaçãoàs etnias com as quais conviveram.

Para o historiador Carlos Zeron, que escreve a orelha do livro, o trabaIho de Amoroso primajustamente pelas"pontes"queestabelececom outros períodos históricos. De um lado, o modelo de catequese capuchinha é obrigado a dialogar com a tradição colonial jesuítica, que vigeu no Brasil durante cerca de 200 anos. De outro, a realidade dos indígenas no Brasil de hoje é tributária de ações de avanço sobre os territórios indígenas no século XIX.

A antropóloga Manuela Carneiro da Cunha, no prefácio do livro, destaca por sua vez as peculiaridades do Brasil do século XIX. Tratava-se de um território que, ainda sob o domínio português, se abriu aos interesses de artistasecientistaseuropeusconvidados pelopríncipe-regenteJoãoVleque culminou com uma política de civilização e catequese de índios a partir de 1845, a qual também previa a vinda de estrangeiros, desta vez padres, sob controle do Estado para se efetivar.

O livro de Amoroso possui uma característica relevante, menos de conteúdo e mais de forma, que eu gostaria de apontar nesta resenha. É uma reflexão que nosajuda a pensara eficácia dosformatos aos quais destinamos nossas pesquisas acadêmicas. Por uma série de motivos profissionais e pessoais, podemos deixar de publicar, em formato de livro, as teses e dissertaçõesque produzimos. Oquenão significa que sejamos pouco produtivos. Ao contrário, desenvolvemos uma série de pesquisas, obtemos financiamento, realizamos trabalhos de campo, vamos a arquivos fora do país, participamos de congressos em diversas partes do mundo. As pesquisas são ricas, como no caso de Marta Amoroso, as análises refinadas, os resultados promissores. No entanto, a exigência de uma produtividade acadêmica que nos remete a uma escala de produção industrial obriga-nos a realizar muito, porém muito fragmentado. Papers em congressos, conferências e comunicações, artigos com número de palavras e páginas estritamente controlado. Com isso, os textosqueproduzimos, peloslimitesimpostospelotempoeespaço,nãoconseguem aprofundar os assuntos, muitas vezes são pinceladas a respeito de 
uma pesquisa maior. A pergunta é: quando, em nosso meio, conseguimos dar a conhecer essa pesquisa maior tanto em tamanho quanto em grau de aprofundamento?

Assim, quando Amorosoopta porpublicarum livroqueéuma coletânea de artigos, acaba trazendo resultados panorâmicos inconclusos. Oleitor fica commuitasindagaçõesqueforammaisbemrespondidasemoutrosartigose na própria tese da autora. Uma das questões, por exemplo, refere-se às articulaçõesearranjos políticosqueestiveram portrás davindadosmissionários capuchinhos ao Brasil, medida efetivada com a lei de 1845 (Decreto 426 de 24/07/1845). Em artigo publicado em 2006 a autora arriscou uma hipótese, bastante plausível, envolvendo o casamento do imperador Pedro II com a princesa Teresa Cristina, de Nápoles, em 1843, demonstrando que a aliança matrimonial tinha também sentido político e estratégico. Daí concluirmos, seguindo os passos da autora, não serporacaso a vinda de trabalhadores imigrantes italianos e padres capuchinhos ao Brasil a partir da segunda metade do Oitocentos. ${ }^{2}$

Adespeito da ressalva, éevidentequeolivroreleva grandesachados. No capítulo 4, por exemplo, a autora inicia uma discussão sobre os termos da legislaçãoindigenistadolmpérioeseusdesdobramentos.Amorosonosmostra que os aldeamentos do período significariam uma "descontinuidade"em relação às ações missionárias cristãs. Para a autora, a política dos aldeamentos do Império (1845-1889) trouxe o conceito de tutela do Estado aos índios e, ao mesmo tempo, propôs que seu direito à terra estivesse atrelado ao grau de "selvageria" (p. 76). Dentro dessa lógica, os antigos aldeados não teriam mais direito de permanecer nas missões. Os Guarani-Kaiowá rapidamente aprenderam a jogar dentro desse esquema: se necessário, antigos aldeados

2 AMOROSO, Marta. Crânios e cachaça: coleções ameríndias e exposição no século XIX. Revista de História $154\left(1^{\circ}, 2006\right), 119-150$ p. 128-30. Disponível em <http://www.revistas.usp.br/revhistoria/ article/viewFile/19024/21087> Último acesso em 07/04/2017. Outros estudos que poderiam ajudar a problematizar a questão: SAMPAIO, Patrícia Melo. Política indigenista no Brasil imperial. In: GRINBERG, Keila; SALLES, Ricardo (Org.). O Brasil imperial. Volume I: 1808-1831. Rio de Janeiro: Civilização Brasileira, 2009; SPOSITO, Fernanda. Nem cidadãos, nem brasileiros. Indígenas na formação do Estado nacional brasileiro e conflitos na província de São Paulo (1822-1845). São Paulo: Alameda, 2012 
"vestiam-se de selvagens" para poder entrar nos novos aldeamentos que se iam fundando (p. 78-80).

No Capítulo 2, Amoroso mostra que o príncipe alemão Maximiliamo Wied-Neuwied,apósumaconvivênciaintensaentreosBotocudos,subverteu o binômio tupi-tapuia no século XIX, ao afirmar que os "botocudos" com osquaisconviveueramtãoamistososquantoostupisdopassado.Adespeito dessa interpretação mais progressista, os cientistas no período se pautavam nos pressupostos da nascente antropologia física, que postulava os princípios da degeneração das espécies da América, crendo que os botocudos se assemelhariam aos animais, pois não tinham chefia, uma liderança como os andinos (p. 43-8).

Já no capítulo 6, Amoroso mostra uma das formas através das quais os franciscanos tiveram êxito no programa de catequese: com a montagem de uma destilaria de aguardente no aldeamento de São Pedro de Alcântara em 1870. O assunto não foi propagandeado, na verdade seguiu oculto no meio da documentação da Ordem Menor (no Arquivo da Custódia dos Padres Capuchinhos do Rio de Janeiro), visto que o consumo de bebidas alcoólicas entre os índios foi sempre uma prática condenada pela religião católica, o queobviamentenãoevitouoseuuso,especialmentedebebidasfermentadas e utilizadas nos rituais indígenas. No caso da cachaça, seu consumo esteve sempre relacionado aos danos que causava às populações indígenas, daí o ocultamento do tema (p. 160-1).

Por fim, Amoroso traz novos aportes para que os especialistas enfrentem uma antiga polêmica. Trata-se da afirmação de Manuela Carneiro da Cunha, escrita no começo dos anos de 1990, de que "questão indígena no século XIX era uma questão de terras":

A "questão indígena", no século XIX, deixou de ser uma questão de mão-de-obra, para se converter essencialmente numa questão de terras. Há variações regionais, é claro: na Amazônia, onde a penúria de capitais locais não permitiu a importação de escravos africanos, o trabalho indígena continuou sendo fundamental, e foi reaviventado no fim do século, com a exploração da balata, da borracha e do caucho. No Mato Grosso e no Paraná, ou mesmo em Minas Gerais e no Espírito Santo, as rotas fluviais a serem descobertas e consolidadas exigiram a submissão dos índios da região. Mas se se pode arriscar falar "em geral" de um século inteiro e do Brasil como um todo, a tônica foi, no século XIX, a conquista de espaço. Em áreas de índios ditos então "bravios", tenta- 
va-se controlá-los, controlando-os em aldeamentos,"desinfestavam-se"assim os sertões. Nas áreas de ocupação colonial antiga, tentavam-se ao contrário extinguir os aldeamentos, liberando as terras para os moradores. Essas diferenças regionais nada mais eram, portanto, do que duas etapas de um mesmo processo de expropriação. ${ }^{3}$

Amoroso demonstra em seu livro que o projeto dos aldeamentos no Paraná a partir da segunda metade do XIX não tinha por objetivo engajar trabalhadores ematividades de interesse dolmpério, mas retirarosíndios de terras e caminhos estratégicos, abrindo espaço para que chegassem outros trabalhadores,comoosimigranteseuropeus, consideradosmaislucrativosno sistema capitalista. Nisso a afirmação de Cunha casa-se com os dados levantados aqui. De todo modo, a análise de Cunha assenta numa generalidade que o próprio trabalho de Amoroso permite contradizer ao exibir inúmeros episódiosemqueosíndiostrabalhavamparaalémdosaldeamentos,especialmente quando já eram considerados "civilizados" e empregavam-se como "camaradas" contratados por jornadas pelos fazendeiros paulistas (p. 173). Além disso, o problema do texto clássico de Manuela Carneiro da Cunha é afirmar isso para o século XIX como um todo, quando estudos mais recentes sobre a primeira metade daquele século vêm mostrando a importância dos índios como mão de obra em várias partes do território brasileiro. ${ }^{4}$

Outro dado importante, que instiga oleitor a compreendermelhor, mas que a autora não fornece maiores dados no livro, ao contrário do que faz na

3 CUNHA,ManuelaCarneiroda.Prólogo.In: (org).Legislação indigenista noséculoXIX.Op.Cit.,p.4

4 Alguns trabalhos mais recentes, no campo da história sobre os índios, abordaram a participação indígena também no trabalho no Brasil império: COSTA, João Paulo Peixoto. Na lei e na guerra: Políticas indígenas e indigenistas no Ceará (1798-1845). Tese de Doutorado. Campinas: IFCH, 2016; LEMOS, Marcelo Sant'ana. O índio virou pó de café? A resistência indígena frente à expansão cafeeira no Vale do Paraíba. Jundiaí: Paco Editorial, 2016; MACHADO, André Roberto de. A quebra da mola real das sociedades: a crise política do Antigo Regime Português na província do Grão-Pará (1821-25). 1. ed. São Paulo: Hucitec / Fapesp, 2010; MOREIRA, Vania Maria Losada. Autogoverno eeconomiamoraldosíndios:liberdade,territorialidadeetrabalho(EspíritoSanto, 1798-1845).Revistade História, n 166, 2012; SPOSITO, Fernanda. Nem cidadãos, nem brasileiros. Op. cit.; XAVIER, Maico Oliveira. Extintosno discurso oficial, vivos no cenário social:osíndios do Cearáno período do império do Brasil. Trabalho, terras e identidades indígenas em questão. Tese de Doutorado. Fortaleza, Universidade Federal do Ceará, 2015. 
tese, é sobre a presença de população de negros nos aldeamentos e em seu entorno. Esse dado gera perguntas no leitor sobre como se dava essa convivência, que papel ocupavam os negros nesse contexto. Na tese de 1998 é possíveldescobriralgunsdadosmaissobreessaspopulaçõesque, noentanto, não são explicados nolivro. Assim, a presença de africanos e afrodescendentesnosaldeamentosesteverelacionadaao envio de trabalhadores especializados, como ferreiros, marceneiros etc. para trabalhar na Fábrica de Ferro de Ipanema em Sorocaba na década de 1850. Não eram necessariamente libertos, mas estavam na condição de "tutela", sofrendoainda castigosfísicos conforme as vontades de seus senhores. ${ }^{5}$

Em síntese, os estudos de Marta Amoroso, em seu conjunto, são de uma qualidade ímpar, de grande importância tanto no campo da História quanto da Antropologia, principalmente na intersecção entre elas. A única coisa a lamentar é que o livro foi muito curto perto dos dados que a autora levantou ao longo das últimas duas décadas.

Recebido: 19/04/2017 - Aprovado: 19/05/2017

5 AMOROSO, Marta. Catequese e evasão. Etnografia do aldeamento indígena de São Pedro de Alcântara, Paraná (1855-1895). Tese de Doutorado em Antropologia. São Paulo: FFLCH-USP, 1998, p. 130-2. 